\title{
Analysis of Financial Statement and Prewarning of Audit Risks Based on Artificial Neural Network
}

\author{
Yanxia Zhang, \\ Ulanqab Vocational College, Ulanqab 012000, China; \\ Email: zhyanxia@126.com
}

Received: March 23, 2021. Revised: August 5, 2021. Accepted: August 20, 2021. Published: August 24, 2021.

\begin{abstract}
The marketization of social capital has resulted in frequent audit failures, and financial statement frauds. One of the key steps of auditing is the identification of material misstatement risk of financial statement. However, there is no unified analysis framework or quantitative method for identifying this risk. Therefore, this paper aims to analyze financial statement and prewarn audit risks in an accurate manner. Firstly, the items of financial statement were analyzed in three aspects of the target enterprise: balance statement, income statement, and cash flow statement. Next, the authors probed deep into the core indices of the post audit risk verification and evaluation of the business process, constructed a scientific evaluation index system for audit risks of financial statement, and quantified the 89 tertiary indices, 21 secondary indices, and 3 primary indices. After that, an audit risk prediction model for financial statement was established based on neural network. Experimental results show the effectiveness of the proposed model for audit risk prewarning, and applicable to other tasks of financial auditing.
\end{abstract}

Keywords-Artificial neural network (ANN), Audit risk evaluation, Financial statement analysis, Audit risk prewarning.

\section{INTRODUCTION}

With the marketization of social capital, enterprises have undergone the complication and diversification of economic businesses and marketing processes. This process is accompanied with frequent audit failures, and financial statement frauds. All these factors have led to a public crisis of trust in the audit quality of certified public accountants (CPAs) [1]-[3]. The main reason for audit failures is that the auditors have neither fully understood the audited enterprise, nor carefully inspected the audit risks of financial statement [4]-[6].

One of the key steps of auditing is the identification of material misstatement risk of financial statement. However, there is no unified analysis framework or quantitative method for identifying this risk. Thus, it is important to fully analyze the financial statement, especially the factors affecting material misstatement risk, the propagation paths of the risk, as well as the formation mechanism of the risk. The analysis results could provide a reference for effective evaluation and prewarning of financial risk, and the practical operations of CPAs in auditing.

The current research on the audit risks of financial statement mainly evolves around the material misstatement risk and control risk [7]-[13]. Lee et al. [14] divided the audit risk factors of financial statement into macro level, industry level, and enterprise level, and regarded the financial distress of the enterprise as a major cause of audit risks of financial statement. Salhi et al. [15] investigated the factors of material misstatement risk for financial statement, including fixed asset conversion rate, innovation level of production technology, and macroeconomic condition, and improved the hierarchical evaluation system for intrinsic risks of financial statement. Based on several aspects of the target enterprise (e.g., organizational structure, formation process of financial information, and transmission channels of that information), Sobolev and Harvey [16] established a factor set of the audit risk for financial statement, and empirically examined the fraud-induced operating risks in audit cycle.

Some domestic and foreign scholars have collected financial statement data with financial fraud, explored deep into the reasons for the fraud, and identified the material misstatement risk of financial statement [17]-[21]. For instance, some scholars have quantitatively evaluated the risk probability. Taking a large industrial enterprise as an example, Bustos et al. [22] selected 12 metrics from the dimensions of enterprise size, 
capital structure, proportion of guarantee amount, operating cash flow, and marketing net profit, conducted logistic regression analysis on these metrics, and pinpointed the fraud in financial statement. Gandy and Veraart [23] took the financial statement data of 32 enterprises as the samples, quantified the probability of material misstatement risk for these financial statements through fuzzy clustering analysis, and achieved a prediction accuracy as high as $78.5 \%$. Lutui and Ahokovi [24] constructed a comprehensive evaluation index system for audit risks, and designed an audit risk evaluation system based on probabilistic analysis, by virtue of the superiority of modern intelligent audit system in data processing.

Some scholars have applied neural networks to the analysis of financial statement. Referring to the financial fraud punishment announcement by regulators like Shenzhen Stock Exchange and Shanghai Stock Exchange, Babaoglu et al. [25] established an audit risk recognition model for financial statement, which involves such influencing factors as enterprise size, financing capability, proportion of connected transactions, and changes in financial personnel and management, and effectively improved the accuracy of risk prediction by combining logistic algorithm with backpropagation neural network (BPNN). From the financial statement data of 54 A-share enterprises listed on Shenzhen Stock Exchange and Shanghai Stock Exchange in 2014-2018, Demina and Dombrovskaya [26] extracted the key financial and non-financial indices as control variables, imported them into a self-designed audit risk evaluation model based on fuzzy neural network, and correctly predicted more than $96 \%$ of all audit risks.

The traditional research mostly concentrates on the audit areas facing the risk of material misstatement. There is little report that balances the audit subject risks with financial statement audit risks. Considering the existing types of audit risks and industrial differences, this paper tries to evaluate the audit risks in actual cases of financial statements.

The foreign studies that analyze financial statement and prewarn audit risks mostly focus on risk-oriented audit methods, risk identification strategies, and the relevant influencing factors. In China, the relevant research started late. The existing risk factor sets proposed by Chinese scholars are not scientific enough or unified. Besides, few Chinese scholars have conducted quantitative or empirical analysis on audit risks.

This paper mainly attempts to analyze financial statement and prewarn audit risks in an accurate manner. Firstly, the items of financial statement were analyzed in three aspects of the target enterprise: balance statement, income statement, and cash flow statement. Next, the authors built a scientific evaluation index system for audit risks of financial statement through an in-depth analysis on the core indices of the post audit risk verification and evaluation of the business process, and quantified the 89 tertiary indices, 21 secondary indices, and 3 primary indices in the system through fuzzy analytic hierarchy process (FAHP). After that, an audit risk prediction model for financial statement was established based on neural network. Finally, the effectiveness of the proposed model for audit risk prewarning was verified through experiments.

The research results are applicable to modern risk-oriented audits. Theoretically, the ANN-based analysis on corporate financial statements creates the conditions for renovating the procedures and methods of financial audit, and, to a certain extent, improves the risk-oriented audit theory. Practically, our audit risk prewarning model can improve the quality and efficiency of audits, and drastically reduce the information risks of financial statements.

\section{II.EXAMPLE ANALYSIS}

This paper analyzes the items of financial statement in three aspects of the target enterprise: balance statement, income statement, and cash flow statement, with the aim to understand the financial status and operating results based on the basic financial information (e.g., production cost, sales profit, assets and liabilities, and cash flow, and to detect the financial vulnerabilities and potential audit risks of the enterprise.

Table 1 shows the state and change trend of monetary funds for the enterprise in 2018-2020. It can be seen that the asset size of the enterprise in 2020 increased by $38.6 \%$ compared with 2018, and 13.4\% compared with 2019. Specifically, deposit and other assets increased from 2019 to 2020 by $13.3 \%$ and $19 \%$, respectively, while cash decreased by $21.8 \%$.

The above data were collected from the regular onsite stock-takings and spot-checks on the enterprise's fixed assets, cash, and deposit by audit units, and the timely verification of bills and balances. The completeness and lawfulness of the relevant records eliminate the audit risks of financial statement to a certain extent.

Table 2 shows the state and change trend of accounts payable in purchase contracts for the enterprise in 2019-2020. The accounts payable in purchase contracts should be items to be paid in the short term. As shown in Table 2, however, the accounts payable in purchase contracts have become the main current liabilities of the enterprise. As of the end of 2020, the balance of accounts payable in purchase contracts of the enterprise stood at 834 million yuan, $18.5 \%$ higher than that of 2019. To prevent the audit risk of long-term open-book tax avoidance, it is necessary to check the long-term term open-book accounts payable, and confirm the actual payment ability.

Table 3 shows the state and change trend of long-term loans for the enterprise in 2018-2020. Obviously, the enterprise saw a continued declined in the scale of long-term loans and the proportion of non-current liabilities. However, the uncertainty of exchange gain/loss might lead to inflated corporate profits, and the risk of overpaying income tax. These two consequences must be checked in a timely manner.

Table 4 shows the state and change trend of bonds payable and interest payments for the enterprise in 2018-2020. In 2020, the enterprise needed to pay a total interest for bonds payable of RMB 178 million yuan. These items must be checked repeatedly, and the relevant vouchers be preserved for audit, in order to prevent the audit risks caused by the starting and 
termination points, and amount of capitalization of the interest for bonds payable.

Tables 5 and 6 show the state and change trend of main business incomes and costs for the enterprise. It can be seen that the main business incomes come from product sales, network service, connected service, and other businesses. Network service was the primary source of income, taking up about $60 \%$ of the total income of the enterprise. Product sales and connected service contributed to $27 \%$ and $10 \%$ of enterprise income, respectively. Network service was the largest cost source of the enterprise, accounting for about $45 \%$ of the total cost. However, the product cost also contributed to as much as $34 \%$ of the total cost, and exhibited a growing trend.

Overall, the main business incomes of the enterprise increased gradually. The network service income was relatively high and stable. All income items depend on business volume, for sales and service prices are both regulated by local financial departments. To avoid the audit risks induced by abnormal incomes and costs, it is important to manage the audit risks associated with the main business incomes and costs, and timely check the income-cost ratio, according to the enterprise's production capacity. Despite its relatively high income, the engineering network service involve complex tax proceedings, calling for attention to its tax audit risks.

Table 7 records the changes of main financial indices of the enterprise. It can be seen that the assets and liabilities dropped to $29.04 \%$; the inventory turnover rate increased to a certain extent; the change rate of main business profits maintained a prominent growth, although the return on assets declined. Hence, it is necessary to verify the data on main business costs and relevant rising expenses, so as to avoid the audit risks of concealing operating incomes or overestimating operating costs.

Table 8 shows the difference rate between the financial indices of the enterprise and the mean values of these indices in the industry. The greater the probability of audit risks, the larger the difference rate. According to industry classification standards, the enterprise mainly engages in the intelligent manufacturing of electronic products and the provision of software services. The mean values of these indices among 10 other enterprises in this industry were taken as the industrial means, and compared with the financial indices of the enterprise, thereby acquiring the corresponding index difference rates.

TABLE I

MONETARY FUNDS OF THE ENTERPRISE.

\begin{tabular}{|c|c|c|c|c|c|}
\hline Item & 2018 & 2019 & Change rate & 2020 & Change rate \\
\hline Cash & 128,200 yuan & 137,300 yuan & $7 \%$ & 107,200 yuan & $-21.8 \%$ \\
\hline Deposit & 3.864 billion yuan & 4.725 billion yuan & $22.3 \%$ & 5.355 billion yuan & $13.3 \%$ \\
\hline Other assets & 183.566 million yuan & 189.239 million yuan & $3 \%$ & 222.152 million yuan & $19 \%$ \\
\hline Total & 3.889 billion yuan & 4.740 billion yuan & $22.1 \%$ & 5.389 billion yuan & $13.4 \%$ \\
\hline
\end{tabular}

TABLE II

ACCOUNTS PAYABLE IN PURCHASE CONTRACTS.

\begin{tabular}{|c|c|c|c|c|}
\hline \multicolumn{2}{|c|}{ Items } & $2019(10,000$ yuan $)$ & $2020(10,000$ yuan $)$ & Change rate \\
\hline \multirow{4}{*}{ Accounts payable } & Project cost & $52,147.63$ & $63,782.10$ & $22.3 \%$ \\
\cline { 2 - 5 } & Raw material cost & $9,456.04$ & $11,526.51$ & $21.8 \%$ \\
\cline { 2 - 5 } & Equipment cost & $5,743.81$ & $5,289.74$ & $-7.9 \%$ \\
\cline { 2 - 5 } & Maintenance cost & 316.17 & 368.96 & $16.7 \%$ \\
\cline { 2 - 5 } & Warranty & $1,437.04$ & $1,129.38$ & $-21.4 \%$ \\
\cline { 2 - 5 } & Environmental protection cost & $1,286.18$ & $1,325.43$ & $3.05 \%$ \\
\cline { 2 - 5 } & Others & 32.94 & 77.59 & $135.5 \%$ \\
\hline & Total & $70,419.50$ & $83,499.09$ & $18.5 \%$ \\
\hline
\end{tabular}

TABLE III

LONG-TERM LOANS.

\begin{tabular}{|c|c|c|c|c|c|}
\hline \multicolumn{2}{|c|}{ Items } & $2018(100$ million $)$ & $2019(100$ million $)$ & $2020(100$ million $)$ & Lending rate \\
\hline \multicolumn{2}{|c|}{ Loan in credit } & 5.49 & 5.45 & 5.52 & $1.98 \%$ \\
\hline \multirow{3}{*}{ Foreign exchange loan } & EUR & 7.20 & 6.04 & 5.96 & \\
\cline { 2 - 5 } & USD & 1.93 & 1.71 & 1.5 & \multirow{2}{*}{ Floating interest rate } \\
\cline { 2 - 5 } & JPY & 0.06 & 0.04 & 0.03 & \\
\hline \multicolumn{2}{|c|}{ Exchange gain/loss } & 2.14 & 0.78 & -0.39 & \\
\hline \multicolumn{2}{|c|}{ Total } & 16.82 & 14.02 & 12.62 & \\
\hline
\end{tabular}


TABLE IV

BONDS PAYABLE AND INTEREST PAYMENTS.

\begin{tabular}{|c|c|c|c|}
\hline Items & $2018(100$ million$)$ & $2019(100$ million $)$ & $2020(100$ million $)$ \\
\hline Bonds payable & 28.70 & 28.70 & 28.70 \\
\hline Interest payments & 1.60 & 1.78 & 1.78 \\
\hline
\end{tabular}

TABLE V

MAIN BUSINESS INCOMES.

\begin{tabular}{|c|c|c|c|c|c|c|}
\hline & \multicolumn{3}{|c|}{2019 (100 million yuan) } & \multicolumn{3}{c|}{$2020(100$ million yuan) } \\
\hline & Amount & Proportion & Change rate & Amount & Proportion & Change rate \\
\hline Product sales income & 9.21 & $27.36 \%$ & $6.98 \%$ & 9.87 & $26.65 \%$ & $7.16 \%$ \\
\hline Network service income & 21.45 & $63.72 \%$ & $4.23 \%$ & 21.9 & $59.14 \%$ & $2.09 \%$ \\
\hline Connected service income & 2.14 & $6.35 \%$ & $91.8 \%$ & 4.79 & $12.93 \%$ & $123.83 \%$ \\
\hline Other incomes & 0.86 & $2.55 \%$ & $-32.54 \%$ & 0.47 & $1.26 \%$ & $-45.34 \%$ \\
\hline Total & 33.66 & $100.00 \%$ & $9.47 \%$ & 37.03 & $100.00 \%$ & $10.01 \%$ \\
\hline
\end{tabular}

TABLE VI

MAIN BUSINESS COSTS.

\begin{tabular}{|c|c|c|c|c|c|c|}
\hline & \multicolumn{3}{|c|}{$2019(100$ million yuan) } & \multicolumn{3}{c|}{$2020(100$ million yuan) } \\
\hline & Amount & Proportion & Change rate & Amount & Proportion & Change rate \\
\hline Product cost & 6.45 & $34.73 \%$ & $6.98 \%$ & 6.87 & $34.23 \%$ & $6.51 \%$ \\
\hline Network service cost & 8.42 & $45.34 \%$ & $4.23 \%$ & 8.93 & $44.49 \%$ & $6.05 \%$ \\
\hline Connected service cost & 3.14 & $16.90 \%$ & $91.8 \%$ & 3.94 & $19.63 \%$ & $25.47 \%$ \\
\hline Other costs & 0.56 & $3.01 \%$ & $-32.54 \%$ & 0.33 & $1.64 \%$ & $-41.07 \%$ \\
\hline Total & 18.57 & $100.00 \%$ & $9.47 \%$ & 20.07 & $100.00 \%$ & $8.07 \%$ \\
\hline
\end{tabular}

TABLE VII

FINANCIAL INDICES.

\begin{tabular}{|c|c|c|c|}
\hline Indices & 2018 & 2019 & 2020 \\
\hline Assets and liabilities & $30.95 \%$ & $32.51 \%$ & $29.04 \%$ \\
\hline Inventory turnover rate & $17.43 \%$ & $16.32 \%$ & $20.78 \%$ \\
\hline Return on assets & $29.23 \%$ & $16.95 \%$ & $16.93 \%$ \\
\hline Change rate of main business incomes & $-0.69 \%$ & $3.87 \%$ & $2.90 \%$ \\
\hline Change rate of main business costs & $-6.62 \%$ & $16.24 \%$ & $7.44 \%$ \\
\hline Chang rate of main business profits & $6.93 \%$ & $-8.25 \%$ & $9.76 \%$ \\
\hline
\end{tabular}

TABLE VIII

COMPARISON BETWEEN FINANCIAL INDICES OF THE ENTERPRISE AND THOSE OF THE INDUSTRY.

\begin{tabular}{|c|c|c|c|c|}
\hline Indices & 2020 (enterprise) & 2020 (industry) & Index difference & Index difference rate \\
\hline Assets and liabilities & $29.04 \%$ & $30.46 \%$ & $1.42 \%$ & $4.61 \%$ \\
\hline Inventory turnover rate & $20.78 \%$ & $21.31 \%$ & $0.53 \%$ & $2.48 \%$ \\
\hline Return on assets & $16.93 \%$ & $13.75 \%$ & $-3.18 \%$ & $23.12 \%$ \\
\hline Change rate of main business incomes & $2.90 \%$ & $2.35 \%$ & $1.15 \%$ & $23.40 \%$ \\
\hline Change rate of main business costs & $7.44 \%$ & $9.48 \%$ & $2.04 \%$ & $21.50 \%$ \\
\hline Chang rate of main business profits & $9.76 \%$ & $8.34 \%$ & $-1.42 \%$ & $17.02 \%$ \\
\hline
\end{tabular}




\section{EVALUATION INDEX SYSTEM}

The audit risk factors of financial statement cover every internal/external disturbance that gives rise to financial statement risks. The example analysis on financial statement indicates that whether the audit risk factors of financial statement can be controlled hinges on the operating risks of the enterprise. Based on the business process, the operating risks mainly include internal resource operation and control strategy risk, business direction and planning risk, and business execution result risk. Therefore, these three risks were investigated deeply as the core indices of the post audit risk verification and evaluation of the business process, and used to build up the following evaluation index system for audit risks of financial statement.

(1) Primary indices

$A R=\left\{A R_{1}, A R_{2}, A R_{3}\right\}=\{$ internal resource operation and control strategy risk, business direction and planning risk, business execution result risk $\}$;

(2) Secondary indices

$A R_{1}=\left\{A R_{11}, A R_{12}, A R_{13}, A R_{14}, A R_{15}, A R_{16}, A R_{17}\right\}=\{$ supplier, distributor, market supply and demand, seasonal impact, production process and technological innovation, legal regulations, environmental protection demand $;$;

$A R_{2}=\left\{A R_{21}, A R_{22}, A R_{23}, A R_{24}, A R_{25}, A R_{26}, A R_{27}, A R_{28}\right.$, $\left.A R_{29}\right\}=\{$ enterprise size, investment strategy, financial management policy, debt repayment mechanism, proportion of connected transactions, financing situation, organizational structure, cash flow, marketing net profit $\}$;

$A R_{3}=\left\{A R_{31}, A R_{32}, A R_{33}, A R_{34}, A R_{35}\right\}=\{$ asset operation effect, internal control effect, rationality of operation direction, completeness of operation planning, operability of operation execution\};

(3) Tertiary indices

$A R_{11}=\left\{A R_{111}, A R_{112}, A R_{113}, A R_{114}, A R_{115}\right\}=\{$ supplier list change, supply contract validity period, supply reliability, supply product quality, settlement conditions $\}$;

$A R_{12}=\left\{A R_{121}, \quad A R_{122}, \quad A R_{123}, \quad A R_{124}\right\}=\{$ distributor type, distributor reliability, sales contract validity period, sales reliability\};

$A R_{13}=\left\{A R_{131}, A R_{132}, A R_{133}, A R_{134}\right\}=\{$ industry attributes, industry development trend, market demand and capacity, core competitiveness $\}$;

$A R_{14}=\left\{A R_{141}, A R_{142}, A R_{143}\right\}=\{$ degree of economic impact, degree of seasonal impact, anti-interference measures $\}$

$A R_{15}=\left\{A R_{151}, A R_{152}\right\}=\{$ advantage of production process, advantage of production technology $\}$;

$A R_{16}=\left\{A R_{161}, A R_{162}, A R_{163}\right\}=\{$ industry fiscal policies, industry tariffs and trade restrictions, industry tax regulations $\}$;

$A R_{17}=\left\{A R_{171}, A R_{172}\right\}=\{$ environmental protection regulations, public opinion $\}$;

$A R_{21}=\left\{A R_{211}, A R_{212}, A R_{213}\right\}=\{$ number of employees, total sales, total assets $\}$;

$A R_{22}=\left\{A R_{221}, A R_{222}, A R_{223}\right\}=\{$ developmental investment strategy, stable investment strategy, retractive investment strategy $\}$

$A R_{23}=\left\{A R_{231}, A R_{232}, A R_{233}, A R_{234}, A R_{235}\right\}=\{$ financial job responsibilities, advanced management system, cheque management, seal management, cash and deposit management $\}$;

$A R_{24}=\left\{A R_{241}, A R_{242}, A R_{243}, A R_{244}\right\}=\{$ controlling project scale, reducing expenditure, disposing assets, introducing social capital $\}$;

$A R_{25}=\left\{A R_{251}, \quad A R_{252}, \quad A R_{253}, \quad A R_{254}, \quad A R_{255}, \quad A R_{256}\right.$, $\left.A R_{257}\right\}=\{$ purchasing other assets, providing or accepting labor services, providing guarantees, providing leases, agency, research and development transfer, license agreement $\}$;

$A R_{26}=\left\{A R_{261}, A R_{262}, A R_{263}, A R_{264}, A R_{265}, A R_{266}\right\}=\{$ bank loan, stock financing, bond financing, financial leasing, overseas financing, pawning $\}$;

$A R_{27}=\left\{A R_{271}, A R_{272}, A R_{273}, A R_{274}, A R_{275}\right\}=\{$ complexity of organizational structure, establishment of business divisions, ownership of audit unit responsibilities, composition of management, share of public ownership $\}$;

$A R_{28}=\left\{A R_{281}, A R_{282}, A R_{283}, A R_{284}\right\}=\{$ fixed assets, current assets, other investment expenses, income from variable prices of original fixed assets $\}$;

$A R_{29}=\left\{A R_{291}, A R_{292}, A R_{293}, A R_{294}\right\}=\{$ gross profit of sales, sales tax, sales cost, sales period expenses $\}$;

$A R_{31}=\left\{A R_{311}, A R_{312}, A R_{313}, A R_{314}, A R_{315}, A R_{316}\right\}=$ merge and acquisition, and asset disposal activities, asset allocation ratio, capital investment activities, asset utilization, asset conversion rate, asset operation efficiency $\}$;

$A R_{32}=\left\{A R_{321}, \quad A R_{322}, \quad A R_{323}, \quad A R_{324}, \quad A R_{325}, \quad A R_{326}\right.$, $\left.A R_{327}\right\}=\{$ organizational structure and division of responsibilities, authorization and approval, accounting records, asset protection, staff quality, budget management, reporting system $\}$;

$A R_{33}=\left\{A R_{331}, \quad A R_{332}, \quad A R_{333}\right\}=\{$ development direction, business scope, business area $\}$;

$A R_{34}=\left\{A R_{341}, A R_{342}, A R_{343}, A R_{344}, A R_{345}, A R_{346}\right\}=\{$ goal setting, overall planning, plan preparation, comparison and optimization, budget determination, comprehensive balancing $\}$;

$A R_{35}=\left\{A R_{351}, A R_{352}, A R_{353}\right\}=\{$ operability of implementing budget indices, operability of key business management plan, cause analysis for failing to complete the plan\}.

The above evaluation index system consists of 89 tertiary indices, 21 secondary indices, and 3 primary indices. Each index in the system was quantified through FAHP. Firstly, a fuzzy risk judgement matrix was constructed. Suppose index $A$ on the current layer is connected with indices $B_{1}, B_{2}, \ldots, B_{N}$ in the next layer. Then, the fuzzy risk judgement matrix can be constructed as:

$$
\left[\begin{array}{cccl}
F_{11} & F_{12} & \cdots & F_{1 N} \\
F_{21} & F_{22} & \cdots & F_{2 N} \\
\vdots & \vdots & \ddots & \vdots \\
F_{N 1} & F_{N 2} & \cdots & F_{N N}
\end{array}\right]
$$


where, $F_{i j}=\left(E_{p-i j}, E_{L-i j}, E_{O-i j}\right)$ is the fuzzy triangular number of the most pessimistic estimate $E_{p-i j}$, most likely estimate $E_{L-i j}$, and most optimistic estimate $E_{O-i j}$ of the importance of indices $B_{i}$ and $B_{j}$ on the lower layer relative to index $A$ on the current layer.

Considering the sheer number of tertiary indices, the complementary matrix $E=\left(E_{i j}\right)_{N{ }_{N}}=\left(E_{p-i j}, E_{L-i j}, E_{O-i j}\right)_{N *_{N}}$ of the fuzzy triangular number must meet the consistency requirements. If the complementary matrix of the most likely estimate $E_{L}=\left(E_{L-i j}\right)_{N{ }^{*} N}$ meets the consistency requirements, then the judgement $E$ must approximately meet the consistency requirements. The comprehensive consistency index $C C I$ can be calculated by:

$$
C C I=\frac{\lambda_{\max }-N}{N-1}
$$

where, $\lambda_{\max }$ is the maximum eigen-root obtained by solving $E \times R=\lambda R ; R=\left(R_{i j}\right)_{N^{*} N}$ is the probability matrix. The consistency index $C I$ can be calculated by:

$$
C I=\frac{C C I}{R C I}
$$

The value of the random consistency index $R C I$ varies with the order of the matrix. Here, the $R C I$ value is set to 5.65. Calculation shows that $E$ meets the consistency requirements, when $C I$ is smaller than 0.1 . If $C I$ is greater than 0.1 , the index data need to be collected again, and the $E_{i j}$ value needs to be adjusted.

Suppose there are $K$ samples of evaluation indices for audit risks of financial statement. Then, the set of complementary matrices of the fuzzy triangular numbers corresponding to sample $k$ can be expressed as $\left\{E^{k} \mid E^{k}=\left(E_{i j}{ }^{k}\right)_{N^{*} N}=\left(E_{p-i j}{ }^{k}, E_{L-i j}{ }^{k}\right.\right.$, $\left.\left.E_{O-i j}{ }^{k}\right)_{N * N}, k=1,2, \ldots, K\right\}$. Then, the single hierarchical arrangement can be completed for the fuzzy risk judgment matrix through four steps:

Step 1. Synthetize the characteristic information on the audit environment of $K$ samples, and calculate $\left(E_{i j}\right)_{N{ }_{N}}$ by:

$$
E_{i j}=\left(\frac{\sum_{k=1}^{K} E_{P-i j}^{k}}{K}, \frac{\sum_{k=1}^{K} E_{L-i j}^{k}}{K}, \frac{\sum_{k=1}^{K} E_{O-i j}^{k}}{K}\right)
$$

Step 2. Compute the fuzzy comprehensive evaluation result of each evaluation index, and calculate the relative weight vector of the normalized index by:

$$
\omega_{i}=\frac{\sum_{j=1}^{N} E_{i j}}{\sum_{i=1}^{N} \sum_{j=1}^{N} E_{i j}}=\left(\frac{\sum_{j=1}^{N} E_{P-i j}}{\sum_{i=1}^{N} \sum_{j=1}^{N} E_{P-i j}}, \frac{\sum_{j=1}^{N} E_{L-i j}}{\sum_{i=1}^{N} \sum_{j=1}^{N} E_{L-i j}}, \frac{\sum_{j=1}^{N} E_{O-i j}}{\sum_{i=1}^{N} \sum_{j=1}^{N} E_{O-i j}}\right)
$$

Step 3. Conduct pairwise comparison of $\omega_{i}(i=1,2, \ldots, N)$, and calculate the element values of the probability matrix $R=\left(R_{i j}\right)_{N * N}$.

Step 4. Sort the evaluation indices by:

$\omega_{i}=\frac{2 \times \sum_{j=1}^{N} R_{i j}}{N^{2}}$

To obtain the importance of indices on each layer relative to the overall goal, the total hierarchical arrangement was conducted for all evaluation indices based on the result of single hierarchical arrangement for the fuzzy risk judgment matrix.

For the $M$ evaluation indices $A_{1}, A_{2}, \ldots, A_{M}$ on the current layer, the weight coefficients of total hierarchical arrangement were configured as $\omega_{A-1}, \omega_{A-2}, \ldots, \omega_{A-M}$. For the indices $B_{1}, B_{2}$, $\ldots, B_{N}$ on the next layer, the weight coefficients of the $M$ single hierarchical arrangements relative to evaluation index $A_{l}$ were configured as $\omega_{B-l 1}, \omega_{B-l 2}, \ldots, \omega_{B-l M}$. Then, the weight coefficients of total hierarchical arrangement of the indices $B_{1}$, $B_{2}, \ldots, B_{N}$ can be calculated by:

$\omega_{B-l}=\sum_{m=1}^{M} \omega_{A-m} \omega_{B-l m} \quad l=1,2, \cdots, N$

\section{AUdiT RISK PREDICTION MODEL}

The workflow of our audit risk prediction model is illustrated in Figure 1 below.

Currently, the audit risks of financial statements are mostly evaluated by analytical hierarchy process (AHP) and fuzzy comprehensive evaluation (FCE). These methods cannot fully utilize the historical data on financial statements. Neither could they achieve highly accurate analysis and prediction.

After the FAHP of the data on the collected indices, the results should be imported to the self-designed neural network for network training and prediction. The competitive learning of the neural network can be realized, if the nodes have lateral inhibitory connections. To adapt to various inputs or input modes, the nodes must be able to make selective finetuning during competitive learning. The self-organizing mapping neural network can adaptively perform one- or two-dimensional discrete mapping of input sample data of any dimension in a topologically ordered manner. As a result, this neural network is suitable for evaluating the audit risks with the indices with total hierarchical arrangement obtained by FAHP. 


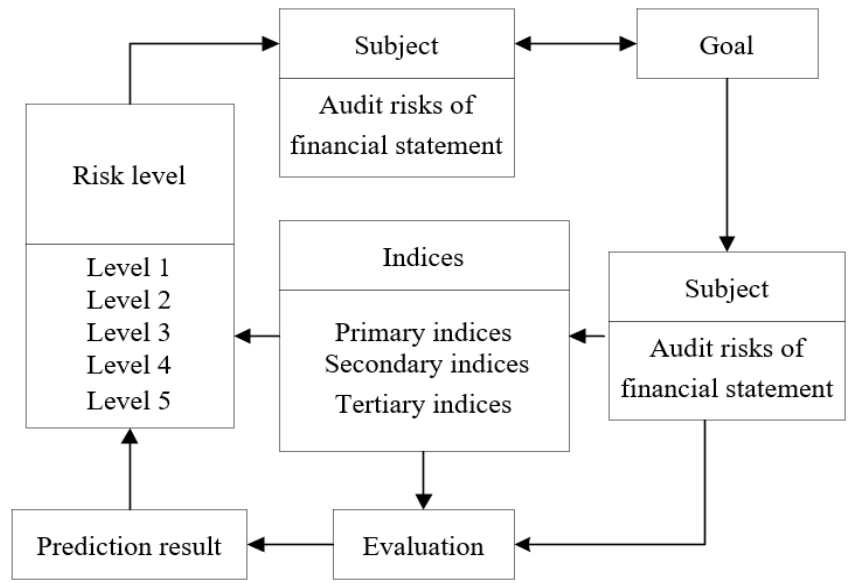

Fig. 1 Flowchart of audit risk prediction model

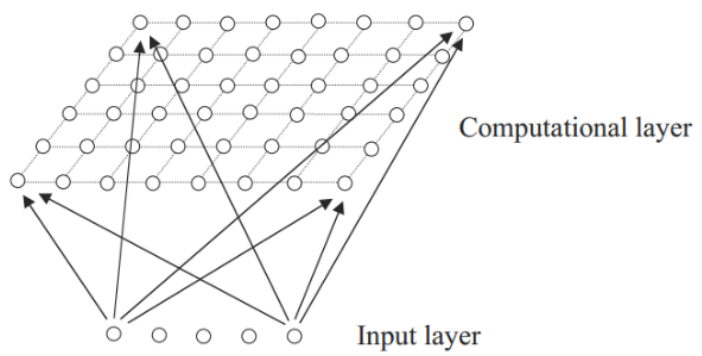

Fig. 2 Structure of Kohonen network

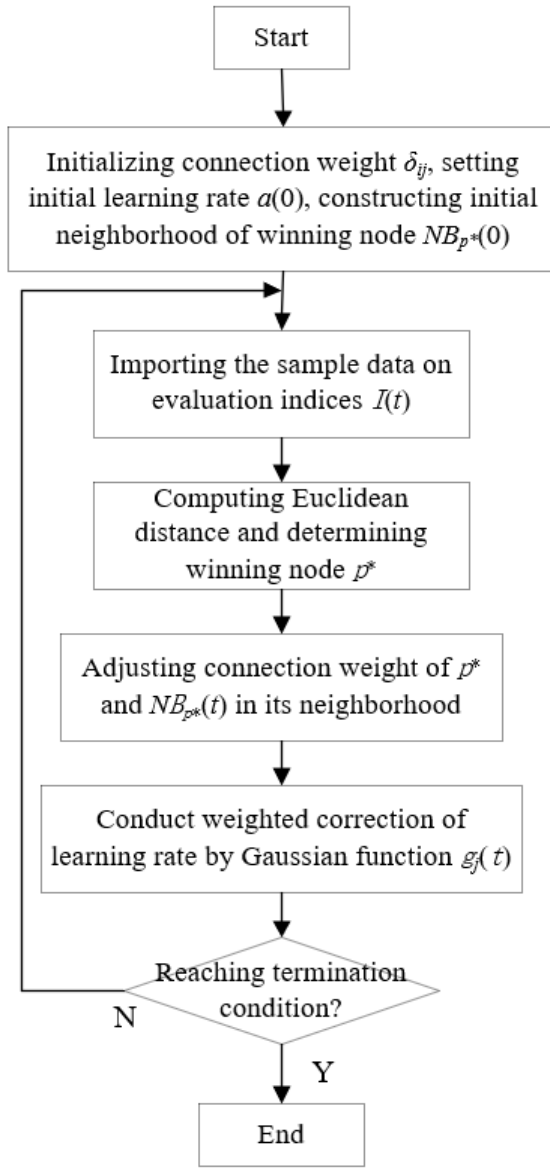

Fig. 3 Training flow of Kohonen network self-organizing mapping neural network.

Suppose the self-organizing mapping neural network has $N_{1}$ input nodes, and 1 output node. That is, the input data on evaluation indices for audit risks have $N_{1}$ dimensions, and only 1 evaluation result on audit risk is outputted. Let $I=\left(I_{1}, I_{2}, \ldots\right.$, $I_{N 1}$ ) be the set of input samples, and $\delta_{i j}$ be the connection weight between input node $\mathrm{i}$ and output node $\mathrm{j}$ on the computational layer. Figure 3 shows the training flow of Kohonen network. The self-organization process mainly covers four aspects: random initialization of connection weights, competition between nodes, cooperation between adjacent nodes, and adjustment of connection weights of activated nodes. The specific steps are as follows:

Step 1. Initialize the connection weight $\delta_{i j}$ as a small random value $\delta_{i j}$; set the initial learning rate $a(0)$; construct the neighborhood $N B_{p} *(0)$ of the initial winning node.

Step 2. Select a sample $I(t)=\left[I_{1}(t), \ldots, I_{N 1}(t)\right]^{T}$ from the input sample set $I$ of evaluation indices at time $t$, and take it as the $N_{1}$-dimensional input vector.

Step 3. Define the discriminant function that wins the competition as the square of the Euclidean distance between the input vector $I(t)$ and the connection weight $\delta_{i j}$ of each node j:

$d_{j}^{2}=\sum_{i=1}^{N_{l}}\left(X_{i}(t)-\delta_{i j}(t)\right)^{2}$

Judge the node whose $\delta_{i j}$ is the closet to $I(t)$ as the winning node $p^{*}$, corresponding to the minimum Euclidean distance. In this way, the mapping between continuous input space and discrete output space can be realized simply through node competition.

Step 4. Adjust the connection weights of only the winning node $p^{*}$ and the nodes in its neighborhood $N B_{p^{*}}(t)$ :

$\delta_{i j}(t+1)=\left\{\begin{array}{l}\delta_{i j}(t)+a(t)\left\lfloor I_{i}(t)-\delta_{i j}(t)\right\rfloor \\ \delta_{i j}(t)\end{array}\right.$

Let $\sigma_{1}$ be the attenuation constant. Then, the value of $N B_{p^{*}}(t)$ can be determined by:

$N E_{p^{*}}(t)=N E_{p^{*}-\min }(t)+N E_{p^{*}-\max }(t) e^{-\frac{t}{\sigma_{1}}}$

where, $N B_{p^{*-m i n}}(t)$ and $N B_{p^{*-m a x}}(t)$ are the smallest and largest neighborhoods of $p^{*}$, respectively. From formula (10), it can be seen that the $N B_{p^{*}}(t)$ value gradually decreases with the progression of the learning process.

The learning rate $a(t)$ affects the training time of the neural network, and, to a certain extent, reflects the adjustment amplitude of mean output error of the network. The learning rate can be determined by:

Figure 2 is the structure of Kohonen network, a typical 
$a(t)=a_{\max } e^{-\frac{t}{\sigma_{2}}}$

where, $\sigma_{2}$ is an attenuation constant; $a_{\max }$ is the maximum initial learning rate of network training. Formula (11) shows that the $a(t)$ value gradually decreases with the progression of the learning process.

Step 5. In the above steps, the connection weight was adjusted only for the winning node $p^{*}$ and each node in its neighborhood $N B_{p^{*}}(t)$ in each iteration. If the learning rate $a(t)$ that obeys the same exponential distribution is optimized through weighted correction, then the winning node will have the largest authority for connection weight adjustment. To ensure the winning node has the largest authority in weight adjustment, the learning rate $a(t)$ obeying the same exponential distribution was optimized through weighted correction. Meanwhile, the adjustment magnitude was determined based on the mean output error of the network receiving the input vector. In this way, the authors assured the effect of weight optimization.

The weighted correction of the learning rate can be implemented by the Gaussian function $g_{j}(t)$ :

$g_{j}(t)=e^{-\frac{d_{j}^{2}(t)}{2 \sigma^{2}(t)}}$

This function is the largest on the winning node, and symmetric about that node. If the Euclidean distance approaches infinity, it will decay monotonically to zero. $\sigma^{2}(t)$, which should be decreasing over time, can be expressed by the exponential decay of the common time-dependent relationship: $\sigma^{2}(t)=\sigma_{0}^{2} e^{-\frac{t}{\tau}}$

Normally, $\tau$ value is a constant: $10^{3} \ln \sigma_{0}$. Then, the adjustment function of the connection weight can be updated as:

$\delta_{i j}(t+1)=\delta_{i j}(t)+\alpha(t) g_{j}(t)\left[I_{i}(t)-\delta_{i j}(t)\right]$

Step 6. Repeat Steps 1-4 until the network error converges or the maximum number of iterations is reached.

In the improved self-organizing mapping neural network, the adjustment amplitude of the connection weight ensures the distance between each node and the winning node. The winning node has the largest authority to adjust its connection weights. The adjustment authority decreases with the distance to the winning node.

\section{EXPERIMENTS AND RESULTS ANALYSIS}

Experiments were designed to verify the performance of the proposed neural network in audit risk prewarning. The first task is to validate the effectiveness of the winning node judged by the self-organizing mapping neural network. Figure 4 illustrates the judgement of the winning node. It can be seen that the self-organizing mapping neural network clustered the nodes: the winning node and its neighborhood nodes were assigned to the same cluster. As shown in Figure 5, the network error decreased quickly with the growing number of training cycles, a sign of good convergence.

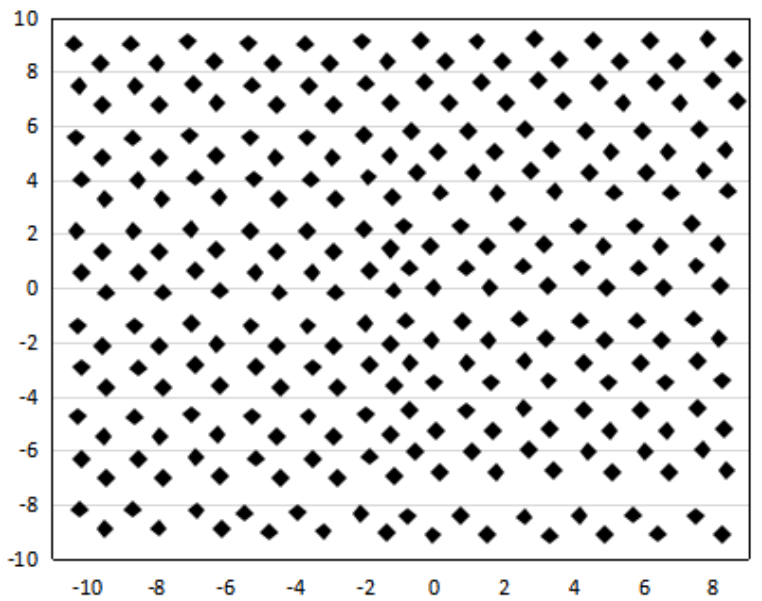

(a) Pre-judgement

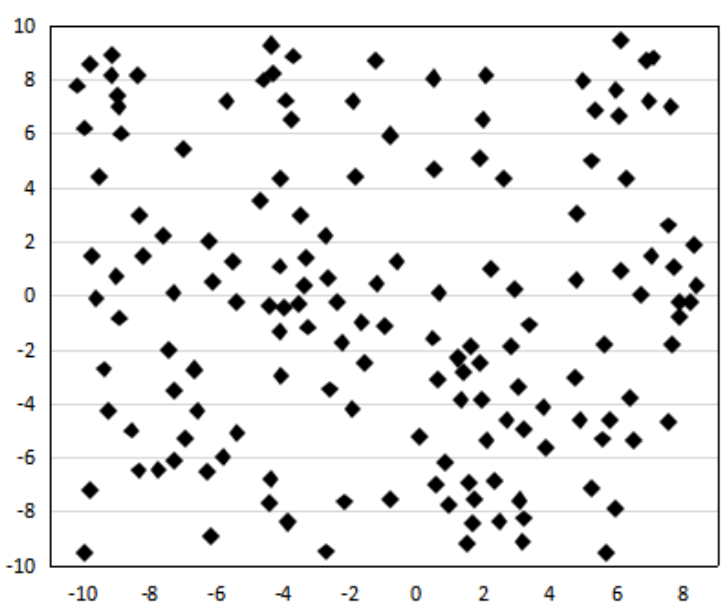

(b) Post-judgement

Fig. 4 Judgement of winning node 


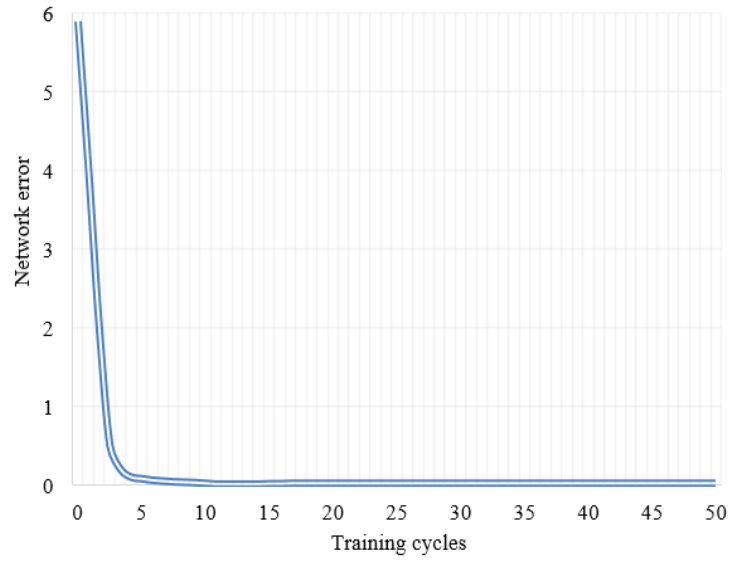

Fig. 5 Convergence of network error

Figure 6 compares our method with artificial neural network (ANN) optimized by particle swarm optimization (PSO) (PSO-ANN), traditional BPNN, and ANN optimized by genetic algorithm (GA) (GA-ANN). Based on the high-dimensional dataset of financial statement audit risk indices, our model converged after only 100 iterations. Thus, our model is faster in convergence than the other models.

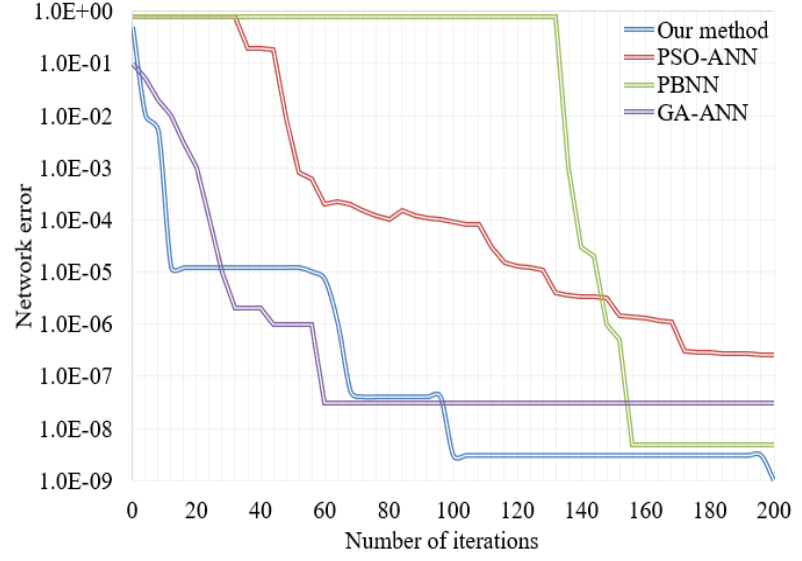

Fig. 6 Prediction errors of different models

Table 9 compares the prediction accuracies of different methods in the training process. Our method achieved the best result on the test set. The best and worst accuracies of our method were $95.93 \%$ and $90.21 \%$, respectively, better than those of any other method. In addition, our method realized the lowest training error and test set. These results fully verify the accuracy and stability of our method in prediction.

Table IX

TRAINING RESULTS OF DIFFERENT METHODS.

\begin{tabular}{|c|c|c|c|c|c|}
\hline Methods & Best accuracy & Worst accuracy & Mean accuracy & MAE & RMSE \\
\hline Our method & $95.93 \%$ & $90.21 \%$ & $93.22 \%$ & $1.14 \mathrm{e}-02$ & $2.41 \mathrm{e}-01$ \\
\hline PSO-ANN & $92.93 \%$ & $87.21 \%$ & $91,79 \%$ & $2.58 \mathrm{e}-02$ & $5.82 \mathrm{e}-01$ \\
\hline BPNN & $89.73 \%$ & $82.84 \%$ & $85.76 \%$ & $5.25 \mathrm{e}-02$ & $7.78 \mathrm{e}-01$ \\
\hline GA-ANN & $93.81 \%$ & $89.07 \%$ & $92.11 \%$ & $2.18 \mathrm{e}-02$ & $4.57 \mathrm{e}-01$ \\
\hline
\end{tabular}

Note: MAE and RMSE are short for mean absolute error and root mean square error, respectively.

After the training, the proposed neural network achieved the best connection weights and thresholds. Then, the test data in the evaluation index dataset were adopted to test the audit risk prewarning effect of our method. Figure 7 compares the predicted classes before and after learning rate optimization. After the optimization, $93.37 \%$ of all risks were correctly predicted. Prewarning only failed 8 times. All these results were better than those of other methods.

In summary, the proposed self-organizing mapping neural network is more feasible and effective than other methods in prewarning the audit risks of financial statement, and achieved better convergence speed, classification of audit risks, prediction accuracy, prediction stability, and prediction error.

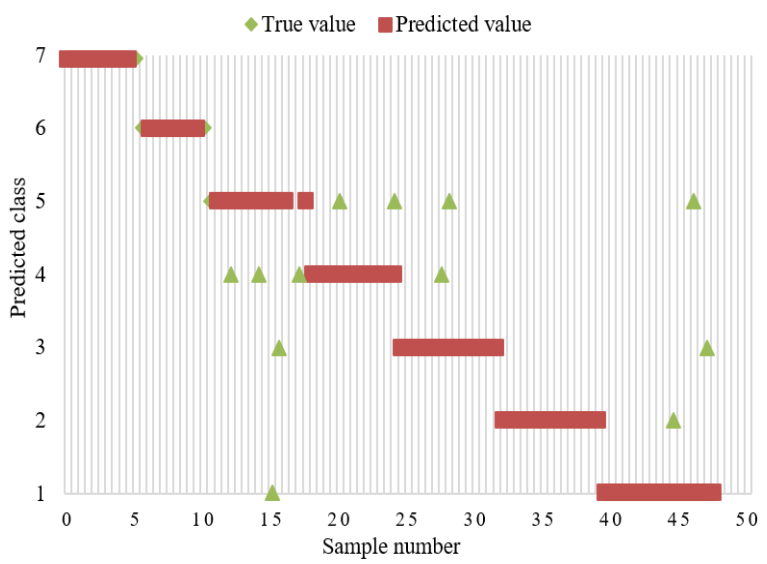

(a) Pre-optimization

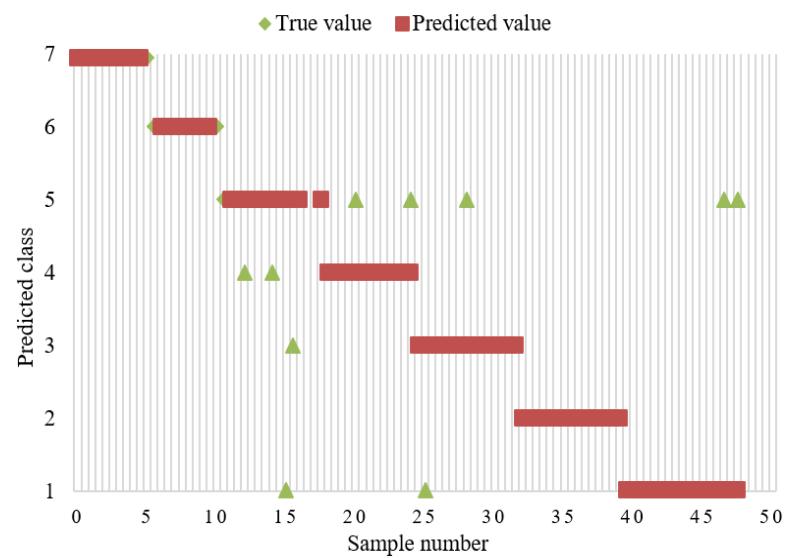

(b) Post-optimization

Fig. 7 Predicted classes before and after optimization of learning rate 


\section{CONCLUSIONS}

Through an example analysis on financial statement, this paper presents an audit risk prewarning model for financial statement based on the ANN. Firstly, the items of financial statement were analyzed thoroughly from three aspects: balance statement, income statement, and cash flow statement. Next, the authors probed deep into the core indices of the post audit risk verification and evaluation of the business process, constructed a scientific evaluation index system for audit risks of financial statement, and conducted FAHP to quantify the 89 tertiary indices, 21 secondary indices, and 3 primary indices. Then, an audit risk prediction model for financial statement was established based on neural network. Then, our method was compared with PSO-ANN, BPNN, and GA-ANN through experiments. The three contrastive methods are all capable of predicting and classifying the audit risks. Through the experiments, the four models were compared in terms of prediction error, and training results. Besides, the predicted classes of our model before and after the optimization of learning rate were contrasted. The results show that PSO-ANN, BPNN, and GA-ANN were poor in prediction and stability, and slow in convergence. Besides, compared with other methods, our method is feasible and effective in prewarning the audit risks of financial statement, and excellent in convergence speed, classification of audit risks, prediction accuracy, prediction stability, and prediction error.

\section{REFERENCES}

[1] R. Bashir, R. Rajeev, A. Shatarah, and N. Bashir, "A Risk Score Analysis Related to Money Laundering in Financial Institutions Across Nations," 2020 8th International Conference on Reliability, Infocom Technologies and Optimization (Trends and Future Directions) (ICRITO), Noida, India, pp. 940-943, 2020.

[2] F. Assef, M.T. Steiner, P.J.S. Neto, D.G. de Barros Franco, "Classification Algorithms in Financial Application: Credit Risk Analysis on Legal Entities," IEEE Latin America Transactions, vol. 17, no. 10, pp. 1733-1740, 2019.

[3] O.V. Smirnova and V.Y. Kotlyar, "Some Models of Exchange Trading in High-Risk Financial Market", Cybernetics and Systems Analysis, vol. 55, no. 4, pp. 661-666, 2019.

[4] T. Busch, "Industrial Ecology, Climate Adaptation, and Financial Risk", Journal of Industrial Ecology, vol. 24, no. 2, pp. 285-290, 2020.

[5] H. Jin, S. Liu, C. Liu, N. Udawatta, "Optimizing the Concession Period of PPP Projects for Fair Allocation of Financial Risk", Engineering, Construction and Architectural Management, vol. 26, no. 10, pp. 2347-2363, 2019.

[6] S. Sabanov, N. Madani, Z. Mukhamedyarova, and Y. Tussupbekov, "A Risk Analysis Method for Estimation of Financial Benefits of the Existing Mine Ventilation System", Mining, Metallurgy \& Exploration, vol. 37, pp. 1137-1149, 2020.

[7] F. Holzmeister, J. Huber, M. Kirchler, F. Lindner, U. Weitzel, and S. Zeisberger, "What Drives Risk Perception? a Global Survey with Financial Professionals and Laypeople", Management Science, vol. 66, no. 9, pp. 3977-4002, 2020.

[8] R. Gerrard, M. Hiabu, I. Kyriakou, and J.P. Nielsen, "Communication and Personal Selection of Pension Saver's Financial Risk", European Journal of Operational Research, vol. 274, no. 3, pp. 1102-1111.

[9] P. Ristau and L. Krain, "Real Time Financial Risk Monitoring as a Data-intensive Application", CLOSER, pp. 660-665, 2019.

[10] C.A. de Assis, M.C. Iglesias, M. Bilodeau, D. Johnson, R. Phillips, M.S. Peresin, R. and Gonzalez, R., "Cellulose Micro - and Nanofibrils
(CMNF) Manufacturing-Financial and Risk Assessment", Biofuels, Bioproducts and Biorefining, vol. 12, no. 2, pp. 251-264, 2017.

[11] N. Liu, P. Wang, and J. Dong, "The Quantile Regression - Mixture Copula Model Applied in the Financial Tail Risk Contagion", IPPTA: Quarterly Journal of Indian Pulp and Paper Technical Association, vol. 30, no. 4, pp. 371-382, 2018.

[12] A. Zemánková, "Artificial Intelligence and Blockchain in Audit and Accounting: Literature Review", WSEAS Transactions on Business and Economics, vol. 16, pp. 568-581, 2019.

[13] S.D. Utomo, Z. Machmuddah, and I.D. Pamungkas, "The Effect of Litigation Risk and Audit Quality on Earning Management: Evidence in Indonesia", WSEAS Transactions on Business and Economics, vol. 16, pp. 328-336, 2019.

[14] Y. Lee, D. Rösch, and H. Scheule, "Accuracy of Mortgage Portfolio Risk Forecasts During Financial Crises", European Journal of Operational Research, vol. 249, no. 2, pp. 440-456, 2016.

[15] K. Salhi, M. Deaconu, A. Lejay, N. Champagnat, and N. Navet, "Regime Switching Model for Financial Data: Empirical Risk Analysis", Physica A: Statistical Mechanics and its Applications, vol. 461, pp. 148-157, 2016.

[16] D. Sobolev and N. Harvey, "Assessing Risk in Graphically Presented Financial Series", Risk Analysis, vol. 36, no. 12, pp. 2216-2232, 2016.

[17] Y. Cao, D. Wu, L. Li, "Debt Risk Analysis of Non-financial Corporates Using Two-tier Networks", Industrial Management \& Data Systems, vol. 120, no. 7, pp. 1287-1307, 2020.

[18] H. Shin and R. Baldick, "Mitigating Market Risk for Wind Power Providers Via Financial Risk Exchange", Energy Economics, vol. 71, pp. 344-358, 2018.

[19] H. Zhang and Y. Zhang, "Risk Accumulation and Evolution of New Financial Platform Under the Obfuscation Strategy", Xitong Gongcheng Lilun yu Shijian/System Engineering Theory and Practice, vol. 38, no. 8 , pp. 1960-1967, 2018.

[20] Y. Yoshida, "An Optimal Process for Average Value-at-risk Portfolios in Financial Management", International Conference on Applied Physics, System Science and Computers, Dubrovnik, Croatia, pp. 101-107, 2017.

[21] J. Organ and L. Stapleton, "The Control of Human Factors in Catastrophic Financial Systems Risk: A Case Study of the Irish Banking Crisis", IFAC-PapersOnLine, vol. 51, no. 30, pp. 580-585, 2018.

[22] C. Bustos., D. Watts, M. Ayala, "Financial Risk Reduction in Photovoltaic Projects Through Ocean-atmospheric Oscillations Modeling", Renewable and Sustainable Energy Reviews, vol. 74, pp. 548-568, 2017.

[23] A. Gandy and L.A. Veraart, "A Bayesian Methodology for Systemic Risk Assessment in Financial Networks", Management Science, vol. 63, no. 12, pp. 4428-4446, 2016.

[24] R. Lutui and T.A. Ahokovi, "Financial Fraud Risk Management and Corporate Governance", The Proceedings of 15th Australian Information Security Management Conference, Perth, Western Australia, pp. 5-13, 2017.

[25] C. Babaoglu, U. Ahmad, A. Durrani, A. Bener, "Predictive Modeling of Lapse Risk: An International Financial Services Case Study", 2017 IEEE International Conference on Systems, Man, and Cybernetics (SMC), Banff, $A B$, pp. 16-21.

[26] I. Demina and E. Dombrovskaya, "Generating Risk-based Financial Reporting", The 2018 International Conference on Digital Science, Budva, Montenegro, pp. 387-399, 2019.

Yanxia Zhang, graduated from Inner Mongolia University of Technology, has obtained a master's degree in business administration, and now works in the Department of Economics and Management of Ulanqab Vocational College and has been engaged in frontline teaching for many years. The main research directions include financial analysis and management accounting.

\section{Creative Commons Attribution License 4.0 (Attribution 4.0 International, CC BY 4.0)}

This article is published under the terms of the Creative Commons Attribution License 4.0

https://creativecommons.org/licenses/by/4.0/deed.en_US 